\title{
Argentaffin cells in ulcerative colitis
}

\author{
J. M. SKINNER, R. WHITEHEAD, AND JUAN PIRIS \\ From the Department of Pathology, Radcliffe Infirmary, Oxford
}

SUMMARY The number of argentaffin cells have been counted in the epithelium of rectal biopsies taken from a series of patients with ulcerative colitis and a control group. The number of argentaffin cells was decreased in ulcerative colitis, but this decrease was not related either to the severity of the inflammation or to the duration of illness.

The secretory products of argentaffin cells have an effect on smooth muscle and bowel motility (Bülbring and Lin, 1958; Haverback and Davidson, 1958; Bülbring and Gershon, 1967; Håkanson, 1970) and may be concerned in the inflammatory response (Sommers, 1966). Obvious inflammatory changes in the mucosa and abnormalities in the smooth muscle of the bowel are characteristic of ulcerative colitis and the morphological abnormalities in the muscle are thought to be a factor in its pathogenesis (Morson, 1969). It is thus surprising that information concerning the argentaffin cell population of the large bowel mucosa in ulcerative colitis is scant. Watson and Roy (1960), who were primarily interested in Paneth cell changes in ulcerative colitis, gained the impression that argentaffin cells were increased in number. Verity, Mellunkoff, Frankland, and Greipel (1962), using a simple quantitative method, showed a decrease in number and correlated this with low levels of mucosal 5-hydroxytryptamine estimated biochemically. Because the argentaffin cell population in the bowel is known to vary from place to place (Hamperl, 1932; Erspamer and Asero, 1952; Singh, 1966), we have quantitated argentaffin cells in ulcerative colitis in rectal biopsies taken from a standard site and related the counts to length of history and severity of mucosal inflammation.

\section{Material and Methods}

Rectal biopsies, which included the muscularis mucosa and taken between $12-15 \mathrm{~cm}$ from the anal margin, were used.

The control group consisted of 31 biopsy specimens from patients shown to be sigmoidoscopically and radiologically free from ulcerative colitis. Any suspected cases of the irritable colon Received for publication 25 May 1971. syndrome were excluded. The histological appearances were normal in sections routinely stained with haematoxylin and eosin.

The ulcerative colitis group were patients in whom a firm diagnosis had been made on a combination of clinical, radiological, and histological grounds. The length of history from the onset of the first symptoms was recorded and the cases were divided into three groups: (1) those with the disease for less than one year; (2) those with the disease for more than one year but less than five years; and (3) those with the disease for more than five years.

Accurate information concerning the number of relapses was impossible to obtain and this factor was not studied.

\section{ROUTINE HISTOLOGICAL EXAMINATION}

The biopsy specimens were graded into three groups on a simple estimate of the severity of the inflammatory reaction.

\section{Severe inflammation}

In this group of 68 patients there was a heavy infiltration of the lamina propria by plasma cells, neutrophils, eosinophils, and some lymphocytes. In addition, there was dilatation of blood vessels, capillary margination of polymorphs, and migration of polymorphs through the crypt epithelium forming crypt abscesses. Ulceration was sometimes present.

\section{Moderate inflammation}

In this group of 31 patients there was an increase in the number of inflammatory cells in the lamina propria, mainly of plasma cell type. The more marked vascular changes and crypt abscess formation were absent.

\section{No significant inflammation}

A group of biopsies from 16 patients with chronic 636 
ulcerative colitis showing no significant inflammatory infiltration in the lamina propria. As in the other two groups epithelial changes such as a decrease in goblet cells and irregularity and atrophy of crypts may be present.

\section{QUANTITATIVE HISTOLOGICAL EXAMINATION}

Sections were cut perpendicular to the muscularis mucosa at a thickness of $5 \mu$ and at intervals of approximately $20 \mu$. These were stained by the Fontana silver method in which the argentaffin cells are blackened, and were then lightly counterstained with methylene blue to outline the mucosal structures.

Earlier methods of quantitation of argentaffin cells have relied on numbers of cells per microscopic highpower field (Monesi, 1960), or the numbers of cells in the base of 100 crypts (Verity et al, 1962). Singh (1965) showed that a more accurate estimate was given by relating cells to the basement membrane area. We have chosen to follow this principle, but as a basement membrane is difficult to see in these sections at low magnifications and may be damaged in ulcerative colitis, we have used the epithelial cells lining the surface and crypts as the reference point. Instead of planimetry, as used by Singh, which is tedious and which may be subject to considerable observer error, we used the technique of point counting (Dunnill, 1968).

A Zeiss I $\times 10$ integrating eyepiece was used in conjunction with $\mathrm{a} \times 10$ objective giving a total magnification of $\times 100$. This eyepiece has 25 points arranged at the apices of a regular pattern of equilateral triangles. In each section the first field was chosen at random, subsequent fields were then selected in a regular manner using the microscope mechanical stage. In each field the number of points falling on epithelial cells were counted and these are proportional to the area of the epithelium on which they lie. We chose to count the number of argentaffin cells in the area of epithelium occupied by approximately 200 points (about 20 fields) since we found that the results were the same whether we counted 100 or 1,000 points. The results were arbitrarily expressed as numbers of argentaffin cells per 100 epithelial points, ie, a standard unit of epithelium. Employing this method allows an accurate comparison of a normal mucosa with the mucosa in ulcerative colitis which is often distorted by the inflammatory process; it is not a measurement of absolute numbers.

\section{Results}

The argentaffin cell count in normals as compared with the three histological groups of ulcerative

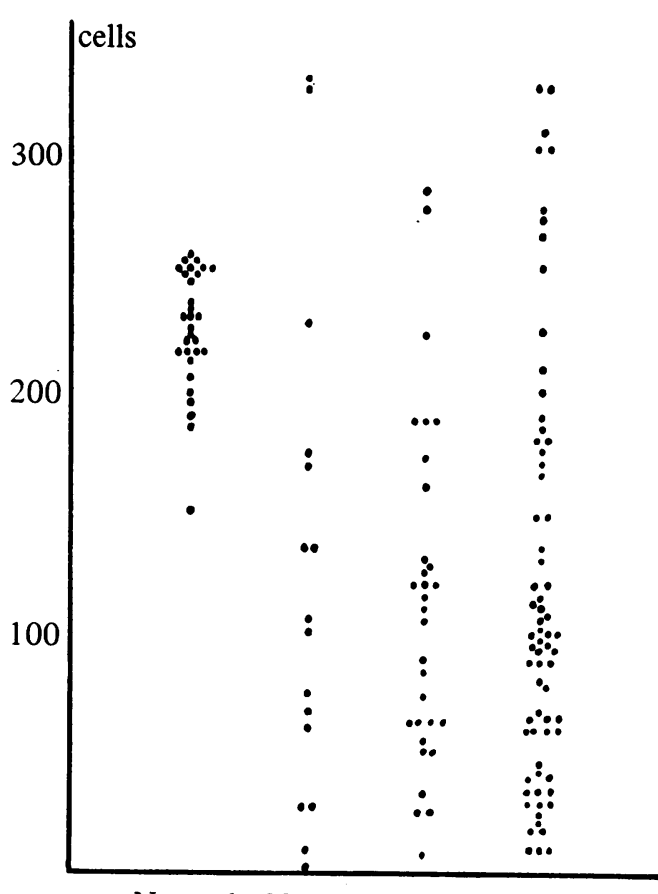

Normal N.S.I. Moderate Severe

Fig. 1. The number of argentaffin cells per unit of epithelium related to severity of inflammation.

colitis is shown in Fig. 1, and with duration of illness in Figure 2.

The mean argentaffin cell count of the control group was $224(\mathrm{SE}= \pm 4.5)$. The mean for no significant inflammation was $115(\mathrm{SE}= \pm 9 \cdot 8)$, for moderate inflammation was $112(\mathrm{SE}= \pm 26.5)$, and for severe inflammation was 114 (SE $= \pm 10.9$ ). The three groups are significantly different from normal when subjected to Student's $t$ test $(t=8 \cdot 0$, $\mathrm{n}=59, \mathrm{P}<0.001$ for normal compared with the group in which there was no significant inflammation; $t=6.6, n=96, \mathrm{P}<0.001$ for normal compared with the moderate group; and $t=5 \cdot 3$, $\mathrm{n}=44, \mathrm{P}<0.001$ for normal compared with the severe group).

Similarly, when comparing the normal with the ulcerative colitis grouped according to the duration of illness, the mean count for less than one year was 112 (SE \pm 13$)$, for one to five years 157 (SE \pm 19 ), and more than five years $102(S E \pm 12)$. When subjected to Student's $t$ test the comparison of these two groups showed: $t=10.5, n=56, P=<0.001$ for normal compared with less than one year; $t=$ $3.5, \mathrm{n}=57, \mathrm{P}<0.001$ for normal compared with one to five years; and $t=10, n=54, P<0.001$ 




Fig. 2. The number of argentaffin cells per unit of epithelium related to duration of illness.

for normal compared with more than five years. Again the differences appear significant.

\section{Discussion}

As the argentaffin population varies at different sites in the large bowel, we chose to examine biopsies from a single site at a distance of 12 to $15 \mathrm{~cm}$ from the anal margin. The control group shows that this site contains a uniform number of cells per unit of epithelium.

The results also indicate that there is a tendency for argentaffin cells to be reduced in number in ulcerative colitis, but, unlike the findings of Verity et al (1962), we could show no difference in numbers with severity of inflammation or length of history. A possible explanation for this difference may be due to the fact that they did not standardize the site of study to one point of the large bowel.

In the normal mucosa, argentaffin cells appear predominantly at the base of crypts, whereas in ulcerative colitis they are seen at all crypt levels and in the surface epithelium. It is this unusual distribution which may have led Watson and Roy (1960) to suggest that the number of argentaffin cells was increased, and as Verity et al (1962) made their assessment on the base of crypts only, their results are lower than in this study probably for the same reason.

Although 5-hydroxytryptamine (5-HT) is produced in argentaffin cells (Erspamer and Asero, 1952; Barter and Pearse, 1953 and 1955) and has been implicated in the pathogenesis of ulcerative colitis (Sommers, 1966), it is difficult to reconcile this with our results. Repeated severe attacks of inflammation occurring over many years cause depletion in argentaffin cells, and presumably also 5-HT levels; thus if 5-HT is involved in the pathogenesis factors other than the number of argentaffin cells must be involved. It is then unlikely that 5-HT is an initiating factor in ulcerative colitis. The reduction in argentaffin cells is probably the consequence of the mucosal damage, and the relatively lower regenerative capacity of the cells as compared with say Paneth cells or epithelial cells. This could be a reflection of the more complex structure of the cell.

\section{References}

Barter, R., and Pearse, A. G. E. (1953). Detection of 5-hydroxytryptamine in mammalian enterochromaffin cells. Nature (Lond.), 172, 810-811.

Baxter, R., and Pearse, A. G. E. (1955). Mammalian enterochromaffin cells as the source of serotonin (5-hydroxyryptamine) J. Path. Bact., 69, 25-31.

Bülbring, E., and Lin, R. C. Y. (1958). The effect of intraluminal application of 5-hydroxytryptamine and 5-hydroxytryptophan on peristalsis: the local production of 5-HT and its release in relation to intraluminal pressure and propulsive activity. $J$. Physiol. (Lond.), 140, 381-407.

Bülbring, E., and Gershon, M. D. (1967). 5-Hydroxy-tryptamine participation in the vagal inhibitory innervation of the stomach. J. Physiol. (Lond.), 192, 823-846.

Dunnill, M. S. (1968). Quantitative methods in histology. In Recent Advances in Clinical Pathology, edited by S. C. Dyke, vol. 5 , pp. 401-416. Churchill, London.

Erspamer, V., and Asero, B. (1952). Identification of enteramine, the specific hormone of the enterochromaffin cell system, as 5-hydroxytryptamine. Nature (Lond.), 169, 800-801.

Håkanson, R. (1970). New aspects of the formation and function of histamine, 5-hydroxytryptamine and dopamine in gastric mucosa. Acta physiol. scand., Suppl. 340, 35-76.

Hamperl, H. (1932). Was sind argentaffine Zellern. Virchows Arch. path. Anat., 286, 811-833.

Haverback, B. J., and Davidson, J. D. (1958). Serotonin and the gastrointestinal tract. Gastroenterology, 35, 570-578.

Monesi, V. (1960). The appearance of enterochromaffin cells in the intestine of the chick embryo. Acta anat. (Basel), 41, 97-114.

Morson, B. C. (1969). Muscle abnormality in ulcerative colitis. New Engl. J. Med., 281, 325-326.

Singh, I. (1965). Methods of quantitative estimation of enterochromaffin cells. Anat. Anz., 117, 322-326.

Singh, I. (1966). The distribution of cells of the enterochromaffin system in the gastrointestinal tract of human foetuses. Acta anat. (Basel), 64, 544-558.

Sommers, S. C. (1966). Mast cells and Paneth cells in ulcerative colitis. Gastroenterology, 51, 841-850.

Verity, M. A., Mellunkoff, S. M., Frankland, M., and Greipel, M. (1962). Serotonin content and argentaffin and Paneth cell changes in ulcerative colitis. Gastroenterology, 43, 24-31.

Watson, A. J., and Roy, A. D. (1960). Paneth cells in the large intestine in ulcerative colitis. J. Path. Bact., 80, 309-316. 